\title{
Substorm onset location and dipole tilt angle
}

\author{
J. Wanliss \\ Department of Physical Sciences, Embry-Riddle Aeronautical University, Daytona Beach, Florida, USA \\ Received: 16 July 2005 - Revised: 19 December 2005 - Accepted: 21 December 2005 - Published: 23 March 2006
}

\begin{abstract}
From an initial data set of over 200 substorms we have studied a subset of 30 magnetospheric substorms close to magnetic midnight to investigate, in a statistical fashion, the source region of the auroral arc that brightens at the onset of expansive phase. This arc is usually identified as the ionospheric signature of the expansive phase onset that occurs in the magnetotail. All the substorm onsets were identified via ground-based magnetometer and photometer data from the CANOPUS array. Various Tsyganenko global magnetic field models were used to map magnetic field lines from the location of the onset arc out to its greatest radial distance in the magnetotail. The results appear to favour the current disruption model of substorms since the average onset location has an average of 14.1 Earth radii $\left(R_{E}\right)$ and is therefore more consistent with theories that place the onset location in the inner magnetotail. For the narrow range of tilts available our modeling indicates the parameter that appears to strongly influence the location of the substorm onset is the dipole tilt angle; as tilt becomes less negative onsets occur further downtail.
\end{abstract}

Keywords. Magnetospheric physics (Magnetotail; Solar wind-magnetosphere interactions; Storms and substorms)

\section{Introduction}

Magnetospheric substorms feature localized but highly dynamic activity in the magnetosphere-ionosphere system. Observations show that substorm activity includes the stretching and subsequent dipolarization of magnetic field lines, particle injections at geosynchronous orbit, fast magnetotail plasma flows, development of ionospheric currents and intensifications thereof, auroral brightenings with steady equatorward motion followed by rapid intensification and poleward motion, and geomagnetic pulsations (Samson et al., 1992; Baker et al., 1996; Reeves and Henderson, 2001; Reeves et al., 2003; Baker and Li, 2003). The most dramatic fingerprint of the magnetospheric substorm occurs at the onset of expansive phase, characterized in its ionospheric footprint by the explosive brightening and dynamic motion of the

Correspondence to: J. Wanliss

(james.wanliss@erau.edu) most equatorward auroral arc (Samson et al., 1992; Samson, 1994). Substorms comprise a sequence of dynamic events in the magnetosphere of the Earth, usually associated with the initiation of intense auroral displays at high latitudes. They begin with a growth phase, during which energy is stored in the magnetotail in the form of increased magnetic flux. Following this the expansive phase onset is heralded by rapid dissipation of this stored tail energy in the form of enhanced Joule heating and particle precipitation in the ionosphere, and particle acceleration and transport in the magnetotail. Recovery phase is identified by a return of magnetospheric activity to pre-growth phase levels. In terms of a space weather point of view understanding the dynamics of magnetospheric substorms is crucial, especially for the expansive phase, because substorms are phenomena associated primarily with the inner magnetosphere, a region where most operational spacecraft reside.

In the past numerous event studies considered the location in the magnetotail of the expansive phase ignition site or zone (Samson et al., 1992; Pulkkinen et al., 1991, 1995; Kubyshkina et al., 1999; Erickson et al., 2000; Frank and Sigwarth, 2000; Dubyagin, 2003). Several of these studies used satellite data and the Tsyganenko models to study various aspects related to substorms, for example to map ionospheric auroral brightenings to the distant location in the magnetotail. The statistical samples were very small, so for example, in their work Pulkkinen et al. (1995) found it difficult to paint a coherent picture in mapping of individual substorm auroral arcs. While event studies have included estimates of the magnetospheric location of the onset initiation, there is no published report of statistically large and systematic studies that use magnetospheric models to accurately locate the onset site. Neither have there been systematic studies to determine magnetotail onset location as a function of solar cycle, or dipole tilt, which affect the spatial location of important magnetospheric parameters (Zhou et al., 1999). In this paper these issues will be addressed through the use of data from a large number of substorms compiled over the most recent solar cycle. Ground-based optical data will be used to determine onset locations since substorm onsets are most reliably determined through the simultaneous use of both of these data types (Liou et al., 1999; Friedrich et al., 2001).

Published by Copernicus GmbH on behalf of the European Geosciences Union. 
Even though it has been the subject of many studies the mechanism that triggers expansive phase onset, and its magnetospheric location, remains unresolved. Distinguishing between the competing models has been difficult because of the lack of data and partly because most studies use moments that are rarely interpreted in terms of kinetic effects. The near-Earth neutral line model (NENL) proposes that a neutral line is formed a few minutes prior to onset, between 22 to $30 R_{E}$ ). The neutral line causes acceleration of plasma towards the earth. When this flux encounters pressure gradients from the strong dipole magnetic field, a flux pile-up occurs that causes an instability and expansive phase onset (Birn and Hesse, 1996; Shiokawa et al., 1997; Baumjohann et al., 1999; Schödel at al., 2001). A competing model, the current disruption model (CD), proposes that expansive phase onset begins via a current disruption near geosynchronous orbit, followed by the tailward expansion of the current disruption region toward the site of the neutral line in the midtail (Lui, 1991; Ohtani, 1992; Samson, 1998).

The magnetospheric location of the expansive phase onset is important since mechanisms that may be responsible for the onset of instability, for example the Kelvin-Helmholtz instability (Yoon et al., 1996) or the kinetic ballooning instability (Cheng and Lui, 1998), to name only two possible candidates, are strongly dependent upon spatially variable parameters such as plasma density and magnetic field strength. Frank and Sigwarth (2000) and Erickson et al. (2000) used the Polar and CRRES satellites, respectively, to present evidence that expansive phase is triggered as close as 4 to $7 R_{E}$ from the Earth. This was in addition to the evidence from ground-based data presented by Samson et al. (1992), which suggested expansive phase onset occurs between 6 to $10 R_{E}$. Recently, Dubyagin et al. (2003) used data from the FAST satellite and ground-based instruments, along with a mapping via the Tsyganenko magnetic field model (Tsyganenko, $1995)$ to provide evidence of a near-earth breakup location. Jayachandran et al. (2002) investigated the ionospheric location for a large sample of individual substorm events determined from radar. They found that substorms can be initiated near the equatorward boundary of the proton auroral oval, when the interplanetary magnetic field (IMF) is predominantly southward during the growth phase. However, if the IMF was predominantly northward during growth phase, onset occurred far poleward of the equatorward boundary of the proton auroral oval. All indications are that the onset location is usually very close to the Earth.

Auroral particle precipitations and their resulting luminosity signatures form an important key to understanding aspects of coupling between the magnetosphere and ionosphere. Since magnetic field lines in the magnetosphere and ionosphere are topologically connected, in some sense the ionospheric luminosity variations at high latitudes can be thought of as a screen to monitor magnetospheric activity. Charged particles are strongly affected by the geomagnetic field, thus the ionospheric location where these particles precipitate can be used to provide important information about their source in the magnetosphere. The configuration of the magnetosphere determines how particles move in the magnetosphere, and changes in that configuration can contribute to particle acceleration. The ionospheric footprint of the auroral substorm onset indicates the location of one end of a magnetic field line that ultimately maps to the ignition region in the magnetotail. A minimum requirement for high quality mapping is accurate magnetospheric models since the geometry of the magnetosphere implies that small ionospheric footprints, especially at high latitudes, can map to large spatial regions in the magnetosphere. Imprecise magnetic field models can result in predictions of ignition site location that are wayward by many earth radii. The difficulty in pinpointing the ignition site exists because single spacecraft in the magnetosphere cannot reliably locate and time the onset, and two-dimensional ionospheric observations must rely on magnetospheric models to map along magnetic field lines.

Rather than considering detailed event studies, this paper describes the extension of mapping efforts that include multiple substorms from an ionospheric perspective. As was the case for previous small sample event studies (e.g. Samson et al., 1992; Pulkkinen et al., 1991, 1995; Lu et al., 1999; Erickson et al., 2000; Frank and Sigwarth, 2000; Dubyagin, 2003), we trace back from the ionosphere along the magnetic field lines to pinpoint the magnetospheric location of the ignition site. Although it is difficult to accurately map the onset location to the magnetotail, we believe that the statistical nature of the investigation will provide an average onset location consistent with reality. In addition, mapping of the onset arcs from the ionosphere to the plasma sheet was performed with several different models than those used in the studies mentioned above. We employed the empirical magnetospheric magnetic field models of Tsyganenko (1987; 1989; 1995; $2002 \mathrm{a}, \mathrm{b})$, and make comparisons between mappings produced by the various models (hereinafter referred to as T87, T89, T96, T01).

\section{Data selection and analysis procedure}

Data from the CANOPUS magnetometer and photometer arrays (Rostoker et al., 1995) were used to identify the location of substorm expansive phase onset. Most previous studies used Pi2 pulsations to determine onset (e.g. Nagai et al. (1998) and Miyashita et al. (1999) and references therein). But these signatures must be supplemented by additional techniques (Lui et al., 1998; Liou et al., 1999). Friedrich et al. (2001) accurately determined onsets via a combination of $\mathrm{Pi} 2$ signatures, ground magnetic latitude profiles, and the onset of dipolarization as observed in the $486.1 \mathrm{~nm}$ proton emissions. Samson et al. (1992) showed that 486.1 and $557.7-\mathrm{nm}$ emissions from auroral photometers are an excellent visual source for timing onset, with a resolution of 
$\sim 1$ min. This, along with the Pi2 signatures was used as our criteria.

All the events studied here were "isolated" in the sense that the substorms featured a broad period of quiescence prior to the growth and expansive phases. Next, the growth phases all featured no significant activity such as pseudobreakups prior to expansive phase onset, or PBIs close to the onset time. Substorms are associated with a localized region of auroral enhancement that initiates inside the equatorward region of the nightside auroral oval. At onset this region expands poleward and azimuthally. The electron arc that brightens at the expansive phase onset is located in the region of intense proton aurora $(486.1 \mathrm{~nm})$. PBIs are different from substorms in that they are localized in longitude and move equatorward. They do not expand poleward and azimuthally as substorms do. They are thus a relatively local effect, compared to substorms. Their auroral signature typically moves equatorward from the magnetic separatrix (Lyons et al., 2000) and thus originate near the poleward edge of the 630.0-nm emissions (Blanchard et al., 1997). The ionospheric footprint of the plasma sheet can be approximated by the latitudinal extent of the 630.0-nm emission region (Samson, 1994). In consequence the relative latitudinal motions of the meridian scanning photometer 486.1, 557.7, and 630.0-nm emissions usually allows one to discriminate between the different types of activity. Since the photometers are not necessarily always in the proximity of the actual auroral breakup, we chose to analyze events for which the substorm onset occurred within about $90 \mathrm{~min}$ of the Churchill line of the instrument array. Previous studies indicate that this allows the photometers a good view of the onset region and provides clear substorm signatures in the Churchill chain of eight magnetometer stations. On this basis we selected a subset of 30 substorms from the original larger set of several hundred magnetospheric substorms identified in a previous survey of 10 years of photometer data from the CANOPUS array.

As mentioned above, two approaches were followed to identify the substorms. Initially, substorms were identified with data from the Gillam and Rankin photometer stations. Their locations are, respectively, at $\left(56.4^{\circ}, 265.4^{\circ}\right)$ and $\left(62.8^{\circ}, 267.9^{\circ}\right)$ geographic latitude and longitude. Figure 1 shows an example of data for one such substorm, measured during the early hours of 15 November 1992. The photometer data are in the form of emission intensity versus invariant latitude and time, and have a 1-min temporal resolution. The top keogram shows $\mathrm{H} \beta$ emissions at $486.1 \mathrm{~nm}$ from precipitation of protons (tens of $\mathrm{keV}$ ). The middle keogram shows emissions at $557.7 \mathrm{~nm}$ resulting from precipitation of high-energy electrons (several $\mathrm{keV}$ ). The final keogram shows emissions at $630.0 \mathrm{~nm}$ from the precipitation of low-energy electrons (hundreds of eV). Growth phase features slow equatorward motion of the aurora.

To qualify as a substorm expansive phase onset, a clear brightening of the most equatorward auroral arc was required, immediately followed by rapid poleward motion of the aurora, which indicates dipolarization. For this event, expansive phase onset was at 05:33 UT, and the arc that brightened at onset had its center at about $67.2^{\circ}$. The onset location is indicated by the black box. Brightening of the 557.7-nm emissions, from the high-energy precipitating electrons, along with the poleward motion of the 486.1$\mathrm{nm}$ proton emissions, is an excellent marker for expansive phase onset (Samson et al., 1992; Friedrich et al., 2001). Although other substorm onset identifiers exist, for example high-latitude magnetic bays, Pi2 pulsations, dispersionless injections of high-energy particles, several recent studies have shown that timing of onset via these identifiers alone is uncertain due to propagation-related delay (Ohtani, 1999; Liou et al., 1999, 2000, 2001); use of auroral breakup is probably the most accurate of onset signatures. It is prudent not to rely on only one dataset to time expansive phase onset, so the second identifier used was the onset of $\mathrm{Pi} 2$ pulsations (not shown). Even though there are timing uncertainties associated with propagation of $\mathrm{Pi} 2$ pulsations, these impulsive magnetic signatures, along with the optical indicators, frequently serve as an excellent source for timing the onset (Samson et al., 1992; Friedrich et al., 2001). Figure 2 illustrates the $\mathrm{X}$-component magnetic data from the Churchill magnetometer line on 15 November 1992, with a clear negative magnetic bay signature associated with the expansive phase onset. The bay is clearest in the BACK and FCHU station data.

\section{Magnetic field models}

The most widely used empirical magnetospheric models are those developed by N. A. Tsyganenko and his collaborators (Tsyganenko, 1987; Tsyganenko, 1989; Tsyganenko and Peredo, 1994; Tsyganenko, 1995; Tsyganenko, 1996; Tsyganenko, 2002ab). Since substorm time scales are so fast, and the Tsyganenko models are averages, it is not strictly appropriate to use them to study substorms, even though they have been commonly used in this manner, as noted above by many references. During the expansive and recovery phases of substorms it is almost certainly inappropriate to use the Tsyganenko models, since this is when dramatic and highly dynamic processes such as dipolarization and particle injections occur. But the growth phase is quite different. Steady equatorward motion of the auroral oval during growth phase is associated with slow stretching of the inner magnetotail field (Voronkov et al., 1999). We assume that during the growth phase stretching of the tail and plasma sheet thinning take place without a major reconfiguration of magnetic field lines. This is not an unreasonable assumption, and several studies have shown how this is consistent with data observations (Kaufmann, 1987; Wanliss et al., 2000). The important thing to note is that mapping is done during substorm growth phase when slow changes ensure that the models are most likely to provide results within reason. In the past numerous event 


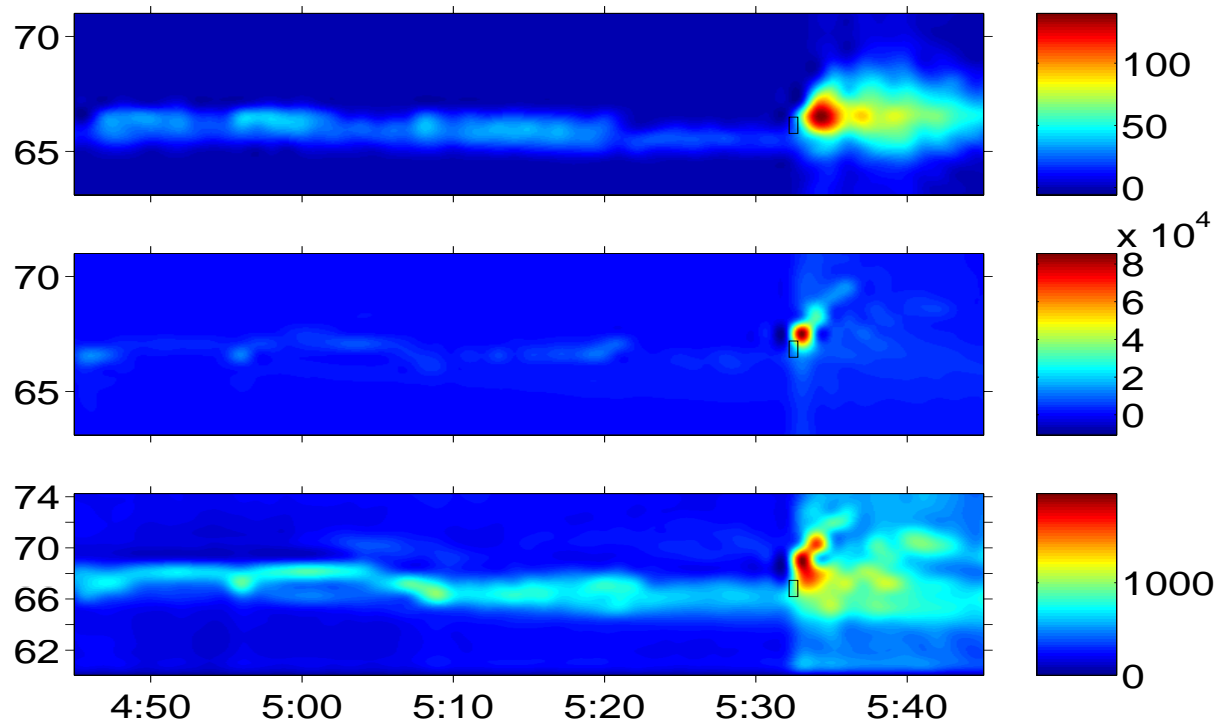

Fig. 1. Meridian scanning photometer keograms from the Gillam photometer on 15 November 1992. The latitudes are expressed in AACGM coordinates, and the brightness scale is measured in Rayleighs. The top panel shows the 486.1-nm emissions, the middle panel shows the 557.7-nm emissions, and the bottom panel shows the 630.0-nm emissions. The location of the onset is indicated by the black boxes in the keograms.

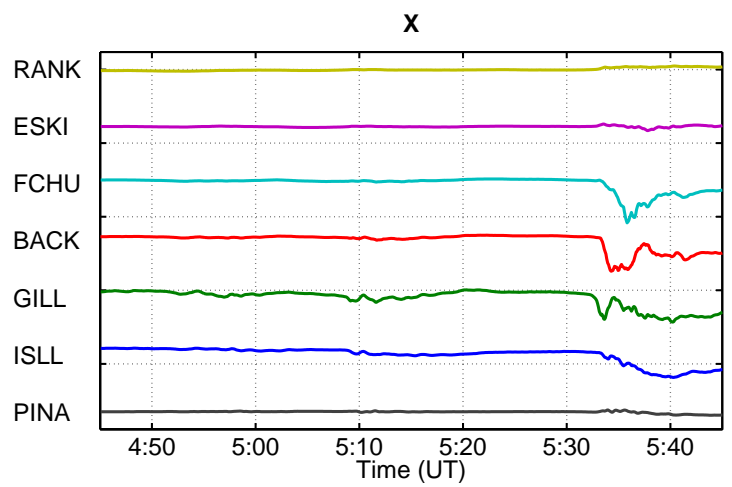

Fig. 2. X-component magnetometer traces from the Churchill line of magnetometer stations on 15 November 1992. A large magnetic bay signature is observed just after 05:30 UT and is particularly clear in the FCHU and BACK data.

studies considered substorms and the location in the magnetotail of the expansive phase ignition site or zone (Samson et al., 1992; Pulkkinen et al., 1991, 1995; Lu et al., 1999; Kubyshkina et al., 1999; Erickson et al., 2000; Frank and Sigwarth, 2000; Dubyagin, 2003). As mentioned previously, the Tsyganenko models were used in several of these substorm studies.

For the purposes of this work we have used T87 (Tsyganenko, 1987), T89 (Tsyganenko, 1989), T96 (Tsyganenko, 1996), and T01 (Tsyganenko, 2002a, b). T01 is supposed to be the most realistic model, especially in mapping the inner magnetotail. We used the other models since T01 is only strictly valid earthward of $15 R_{E}$, and onset sites could be further downtail where the other models are valid. Secondly, even though T01 is ostensibly the best model, it is also the least used. It was not used in any of the event studies listed above, so the results found here could cast a different light on previous work.

Whereas the models prior to T96 did not have a predefined magnetopause and were calibrated exclusively by the magnetic dipole tilt and $\mathrm{Kp}$ index, the T96 and T01 models explicitly include (i) the solar-wind controlled magnetopause, (ii) region 1 and 2 Birkeland currents, and (iii) the interconnection of the magnetospheric and solar wind fields at the boundary. They include further parameterization with the solar wind dynamic pressure, DST-index, and interplanetary magnetic field $B_{y}$ and $B_{z}$.

The earlier models appear to be too stretched in the inner magnetosphere as compared to in-situ observations, particularly during active times. The most recent model, namely $\mathrm{T} 01$, is probably the best suited to determine onset locations, since previous observations suggest that substorm onset occurs in the inner magnetotail. In fact, T01 was intended primarily to improve the description of the inner magnetospheric field $\left(\mathrm{X}>-15 R_{E}\right)$, and unlike the previous models, includes in the modeling database measurements from within geostationary orbit. T01 follows the same approach as in T96, but uses an improved approximation for the ring current field (Tsyganenko, 2000).

Figure 3 shows two different cross-sectional views of model magnetic field lines that map from the ionospheric onset position for the 15 November 1992 substorm. The 
magnetospheric source of the auroral precipitation is understood to map along the corresponding magnetic field line to its greatest radial distance from the Earth. The T87 and T89 models map much closer than do the T96 and T01 models. The latter two models include field-aligned currents which may be responsible for the mapping differences. Furthermore, when mappings are so close to the Earth, it has been shown that T87 and T89 require modifications to take into account the behavior of the inner magnetotail and plasma sheet, which call into question the validity of these earlier models unless suitably modified during late growth phase (Pulkkinen, 1991; Pulkkinen et al., 1995; 1999).

\section{Statistical results}

We performed similar fits as shown above for each of the 30 substorms. Figure 4 shows the distribution of the data for the various variables. The majority of the onsets occurred pre-midnight $(71 \%)$, between $65^{\circ}-72^{\circ}$ in AACGM coordinates (Baker and Wing, 1989). The range for DST was between $-40 \mathrm{nT}$ and $+15 \mathrm{nT}$ for $96 \%$ of the data. This means that the vast majority of the substorms we analyzed do not occur during storms. At the time of onset the interplanetary magnetic field, propagated to the magnetopause, had values for $\mathrm{B}_{y}$ between $-10 \mathrm{nT}$ and $+10 \mathrm{nT}$, and $\mathrm{B}_{z}$ ranges between $5 \mathrm{nT}$ and $+5 \mathrm{nT}$. There is a slight tendency for $\mathrm{B}_{z}<0 \mathrm{nT}$. The dynamic pressure was predominantly less than $5 \mathrm{nPa}(94 \%)$.

Figures 5-9 show how the onset locations are influenced by the various independent parameters. In Fig. 5 the model onset locations are projected onto the X-Y plane. Uncertainties are also indicated; these were computed by mapping the field lines from the ionosphere that were $0.25^{\circ}$ poleward and equatorward of the arc that brightens at onset. Several interesting features are immediately evident; for all models $77 \%$ of the onsets occur on the dusk side of the magnetotail, and each of the pre-midnight onsets map to the dusk side. This means that about $20 \%$ of the postmidnight onsets also map to the dusk side. There is therefore a small, but clear preference for substorms to be initiated in the dusk side magnetotail. This dependence is made more clear in Fig. 6 which shows the onset location for the dawn-dusk coordinate (Y) against magnetic local time. Best fit straight-lines were least-squares fit to these data, and there were strong linear correlations for these data; correlation coefficients were $-0.96,-0.84,-0.78$, -0.81 for $\mathrm{T} 87, \mathrm{~T} 89$, T96, T01, respectively. The relationship is clearest for T87 and T89, but not so clear for MLT <$1 \mathrm{~h}$ before midnight for T96 and T01. In general, the best fit straight-lines indicate that for all models, substorms that are initiated before $30 \mathrm{~min}$ after midnight are initiated on the dusk side of the magnetotail $(Y>0)$. This is an interesting result that indicates some twisting or asymmetry of the magnetotail. Whereas all of the onsets for T87 and T89 occur relatively close to the Earth (within $19 R_{E}$ ), the more recent
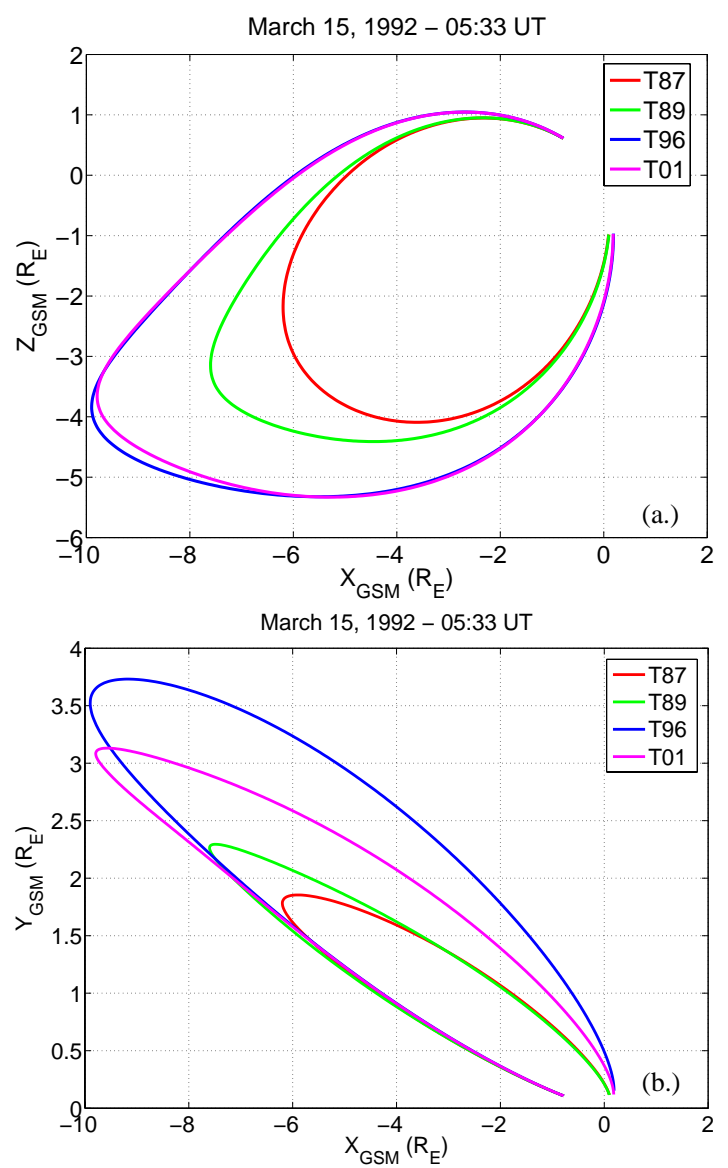

Fig. 3. Meridian plots of the model magnetic field lines mapped from the ionospheric onset location to the magnetotail for the 15 March 1992 substorm.

models that include field-aligned currents feature onsets over a wider range, especially $\mathrm{T} 96$.

Because the differences in the field configuration during quiet and disturbed times are large, it is essential that the effects of varying geomagnetic activity be taken into account in the mapping studies. However, the T87 and T89 models are parameterized by the $K_{p}$ index which is a three-hour average. Thus the veracity of these two models are expected to be inferior to results from T96 and T01. For comparison, for all substorms, the closest onset distance of the magnetic field line which threads the auroral onset position as computed with T87 is $5.3 R_{E}$, compared to $6.0 R_{E}$ for T89. The furthest onset distance for T87 and T89 was $16.0 R_{E}$ and 18.4 $R_{E}$, respectively. The mean onset distances for all substorms were $7.3 R_{E}$ and $9.1 R_{E}$, respectively. These results are consistent with those of Frank and Sigwarth (2000) whose results suggested that substorms may be initiated within the ring current. The statistical results from T96 and T01 were quite different. In some cases the magnetic field lines were very stretched and mapped far downtail, in particular for T96. For all substorms, the minimum and maximum onset 

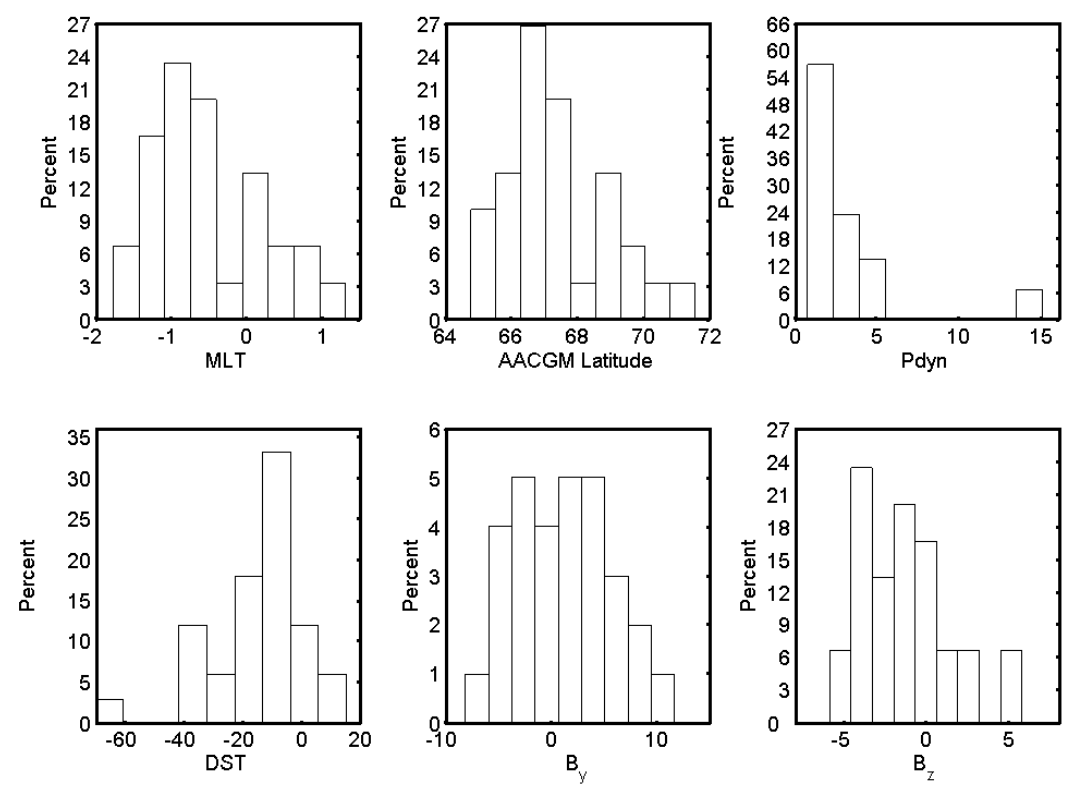

Fig. 4. Histograms showing the distribution of data for various parameters. Abscissas are percent of total number of events.

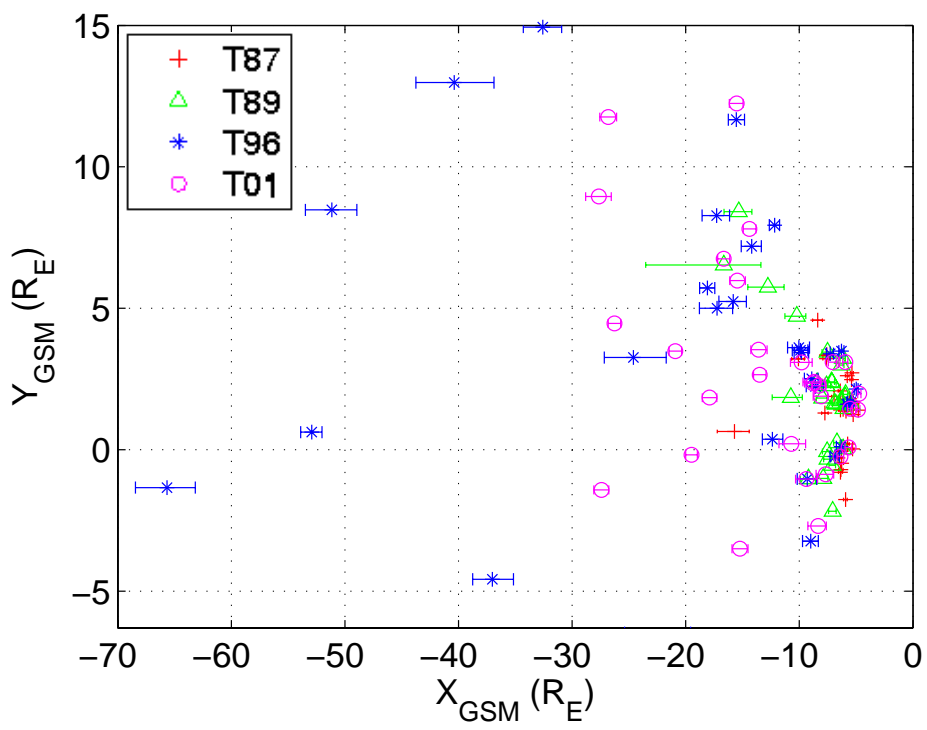

Fig. 5. Location of the model onsets in X-Y plane.

distances for T96 and T01, respectively, were $5.9 R_{E}$ and $5.5 R_{E}$, and $65.8 R_{E}$ and $29.3 \mathrm{R}_{E}$. These results are summarized in Table 1. For all the models, average substorm onset location was inside $20 R_{E}$. Errors for $\mathrm{X}, \mathrm{Y}, \mathrm{Z}$ are indicated on the earthward (positive values, top) and tailward (negative values, bottom) sides of the ignition location. The errors are uneven due to the nonlinear nature of the mapping from the ionosphere to the magnetotail; an error of $\pm 0.25^{\circ}$ can be associated with the onset location in the ionosphere, and because of the stretching of the magnetotail, the error on the high latitude side will typically be larger than for the low latitude. Since there are large outliers, the median values are also important. For the downtail X-position the median values for each model is $-6.2,-7.1,-12.3$, and $-10.2 R_{E}$, respectively.

A few general conclusions are also in order. We found that in general as activity increased as indicated by an increase in $K_{p}$, the location of the substorm onset tends to occur closer to the Earth for T87 and T89 (Fig. 7). A similar qualitative trend is also evident for solar wind dynamic pressure and $\mathrm{B}_{z}$ for the T96 and T01 models (Figs. 8, 9), although there is considerable scatter. 


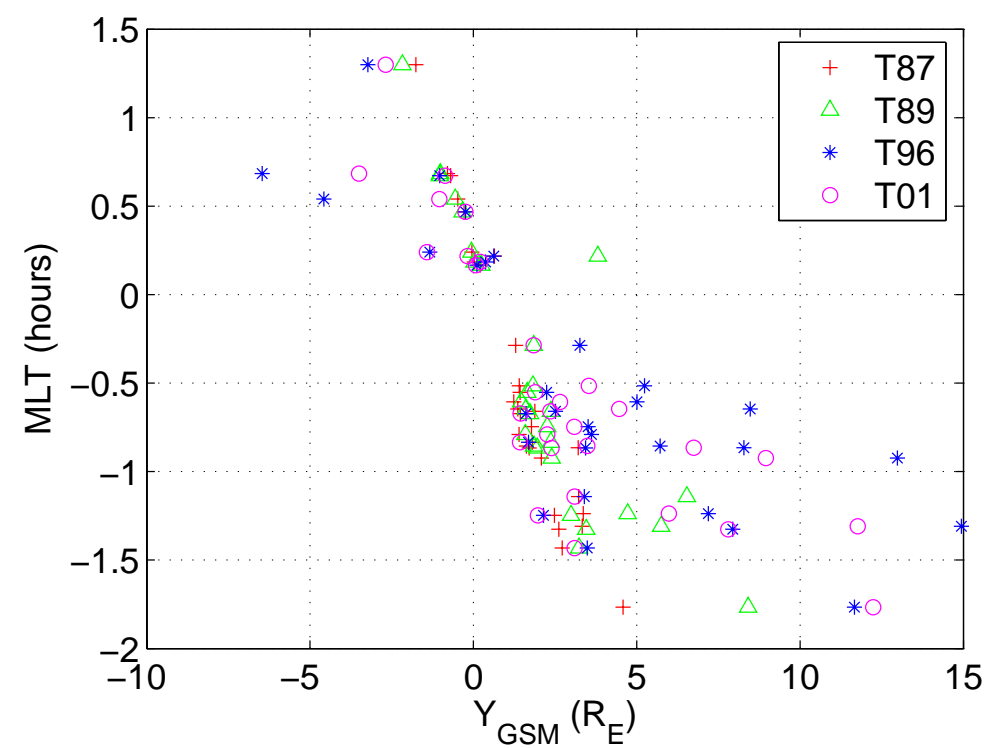

Fig. 6. Onset location for the dawn-dusk coordinate (Y) against magnetic local time.

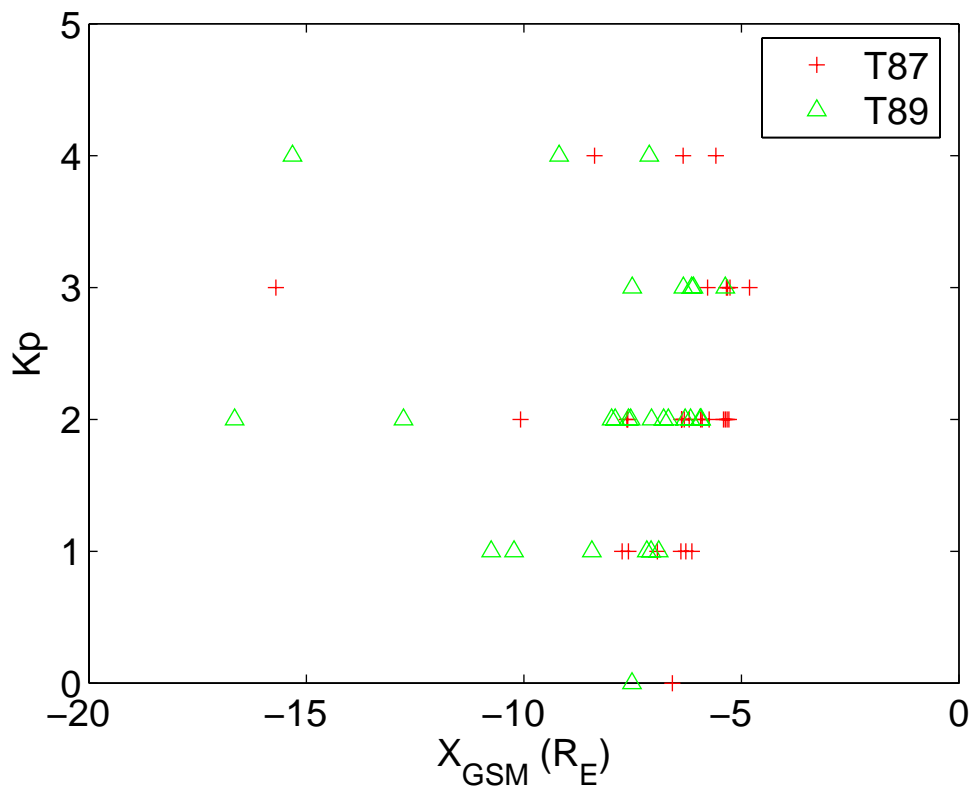

Fig. 7. Dependence of onset location versus $K_{p}$ index.

An interesting relationship appears between onset location and dipole tilt, as indicated in Fig. 10. Close to the Earth an approximately linear trend emerges, and inside $15 R_{E}$ we have modeled onset distance as a function of dipole tilt. The regression coefficients were fitted using a least-squares minimization routine. The results are shown in Table 2, including a notable strong correlation for T96 and T01. Similar comparisons with $K_{p}, D_{s t}, B_{z}$ and dynamic pressure reveal no coherent picture and negligible correlation.

\section{Discussion and conclusions}

From an initial data set of over 200 substorms we have studied a subset of 30 magnetospheric substorms close to magnetic midnight to investigate, in a statistical fashion, the source region of the auroral arc that brightens at the onset of expansive phase. This arc is usually identified as the ionospheric signature of the expansive phase onset that occurs in the magnetotail. All the substorm onsets were identified 


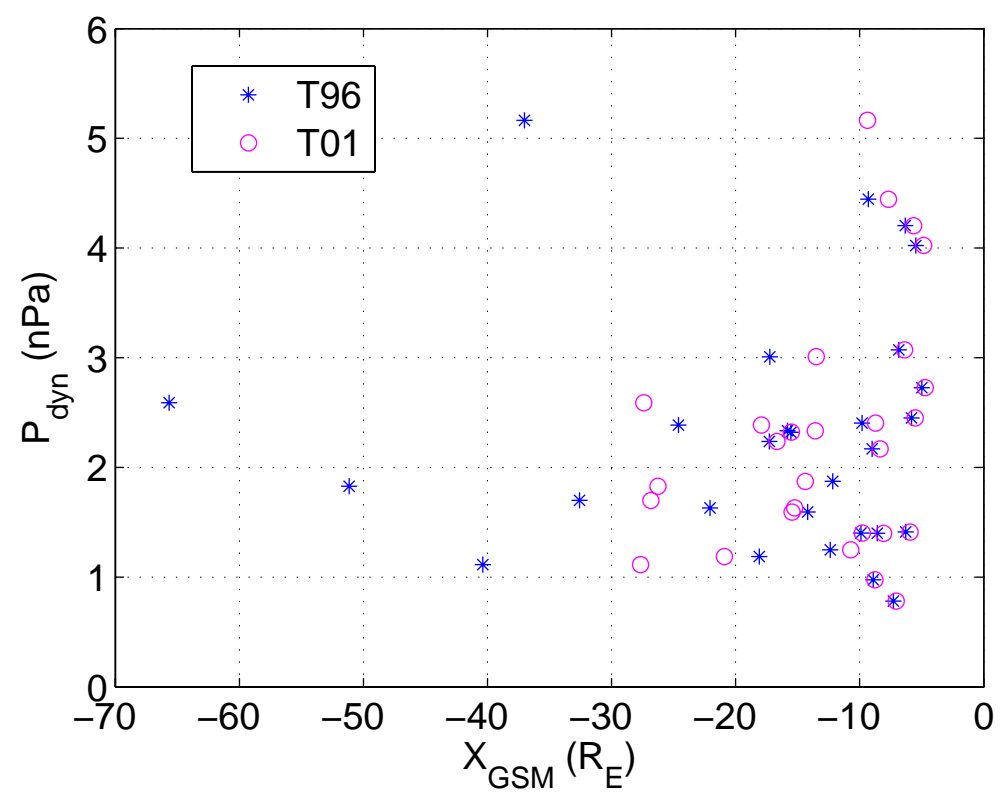

Fig. 8. Dependence of onset location with solar wind dynamic pressure.

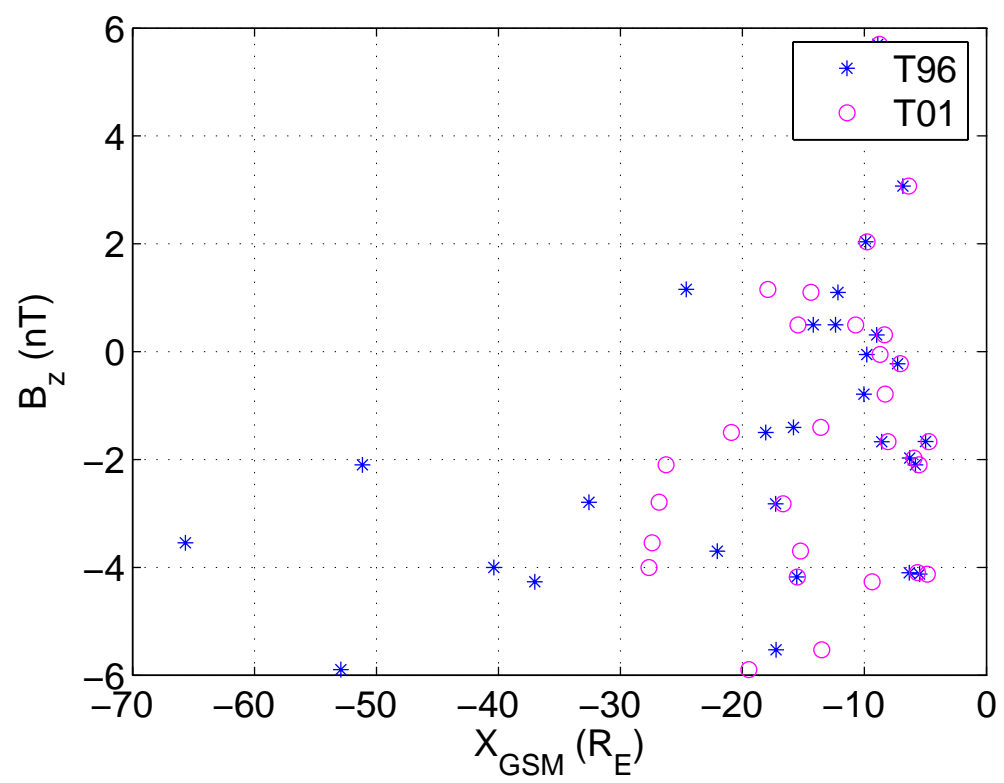

Fig. 9. Dependence of onset location with southward component of interplanetary magnetic field.

via ground-based magnetometer and photometer data from the CANOPUS array. The various Tsyganenko (1987, 1989, 1996, 2002ab) global magnetic field models were used to map magnetic field lines from the location of the onset arc out to its greatest radial distance in the magnetotail.

Previous modeling attempts using the Tsyganenko models have typically indicated undue stretching in the inner magnetotail during substorms. Hence, as the growth phase progresses, mappings from the model magnetotail to the ionosphere result in model ionospheric footprints slightly further north than actually was the case. Mapping from the ionosphere to the magnetotail would correspondingly result in magnetotail locations somewhat closer than actually was the case. They have also indicated that thin current sheets in the inner tail are an important governing component of the overall growth phase dynamics (Pulkkinen et al., 1999; Wanliss et al., 2000, 2002). At substorm onset, the initial disturbance location and timing is sensitively dependent on the stability properties of the thin current sheet (Baker et al., 1996). Because we wished to compare the results from the zero order 
Table 1. Average $(\mathrm{X}, \mathrm{Y}, \mathrm{Z})_{G S M}$ onset locations determined for the T87, T89, T96, and T01 models. The final three columns give the average, minimum, and maximum radial distance of substorm onsets determined for each model.

\begin{tabular}{|c|c|c|c|c|c|c|c|c|c|}
\hline $\begin{array}{c}\text { Mean all } \\
\text { substorms }\end{array}$ & \multicolumn{2}{|c|}{$\mathrm{X}_{\mathrm{GSM}}\left(\mathrm{R}_{\mathrm{E}}\right)$} & \multicolumn{2}{|c|}{$\mathrm{Y}_{\mathrm{GSM}}\left(\mathrm{R}_{\mathrm{E}}\right)$} & \multicolumn{2}{|c|}{$\mathrm{Z}_{\mathrm{GSM}}\left(\mathrm{R}_{\mathrm{E}}\right)$} & $\begin{array}{c}\mathrm{R}_{\mathrm{GSM}} \\
\left(\mathrm{R}_{\mathrm{E}}\right)\end{array}$ & $\begin{array}{l}\mathrm{R}_{\min } \\
\left(\mathrm{R}_{\mathrm{E}}\right)\end{array}$ & $\begin{array}{l}\mathrm{R}_{\max } \\
\left(\mathrm{R}_{\mathrm{E}}\right)\end{array}$ \\
\hline \multirow{2}{*}{ T87 } & \multirow{2}{*}{-6.7} & +0.2 & \multirow{2}{*}{1.4} & +0.1 & \multirow{2}{*}{-2.2} & +0.1 & \multirow{2}{*}{7.3} & \multirow{2}{*}{5.3} & \multirow{2}{*}{16.0} \\
\hline & & -0.2 & & -0.1 & & -0.1 & & & \\
\hline \multirow{2}{*}{ T89 } & \multirow{2}{*}{-8.1} & +0.5 & \multirow{2}{*}{2.0} & +0.2 & \multirow{2}{*}{-3.0} & +0.1 & \multirow{2}{*}{9.1} & \multirow{2}{*}{6.0} & \multirow{2}{*}{18.4} \\
\hline & & -0.8 & & -0.2 & & -0.1 & & & \\
\hline \multirow{2}{*}{ T96 } & \multirow{2}{*}{-18.6} & +1.1 & \multirow{2}{*}{3.4} & +0.2 & \multirow{2}{*}{-3.0} & +0.2 & \multirow{2}{*}{19.9} & \multirow{2}{*}{5.9} & \multirow{2}{*}{65.8} \\
\hline & & -1.1 & & -0.2 & & -0.2 & & & \\
\hline \multirow{2}{*}{ T01 } & \multirow{2}{*}{-13.0} & +0.6 & \multirow{2}{*}{2.8} & +0.1 & \multirow{2}{*}{-3.2} & +0.1 & \multirow{2}{*}{14.1} & \multirow{2}{*}{5.5} & \multirow{2}{*}{29.3} \\
\hline & & -0.6 & & -0.1 & & -0.1 & & & \\
\hline
\end{tabular}

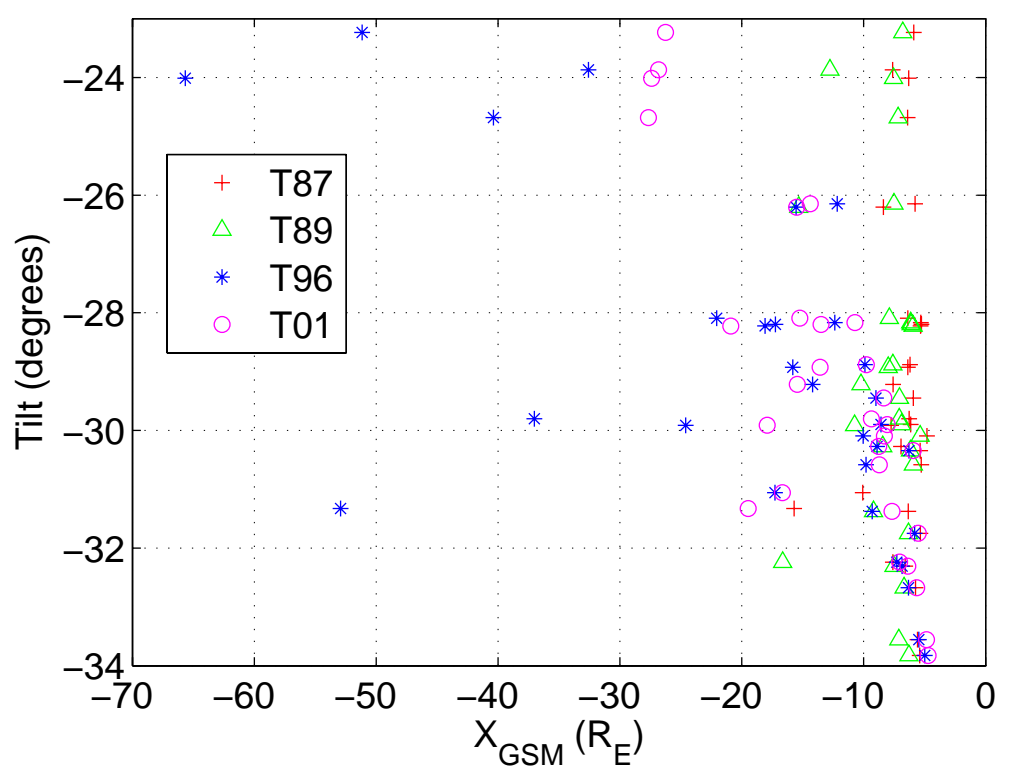

Fig. 10. Dependence of onset location with dipole tilt angle.

Tsyganenko models no modifications were attempted, such as the addition of thin current sheets, even though these are known to produce fields that better mimic the inner magnetotail magnetospheric magnetic field during growth phase (Pulkkinen et al., 1999).

The T96 and T01 models are expected to be the most accurate, partly because they are the most recent models thus more realistic, and partly because they include field-aligned electric currents which are known to strongly affect the magnetic field. In addition, the T87 and T89 models are not, strictly speaking, models of the inner magnetotail for they were not parameterized with data from these regions. The same is true for T96. The only model that is actually parameterized with inner magnetotail data is T01, and we therefore expect that this model will produce results that are most reasonable, especially since we have a priori reason to believe that the onset region is in the inner magnetotail. However, since T01 is not designed to be valid beyond $15 R_{E}$, it is not clear how much further downtail it remains a better model than T96.

Because the differences in the field configuration during quiet and disturbed times are large, it is essential that the effects of varying geomagnetic activity be taken into account in the mapping studies. However, the T87 and T89 models are parameterized by the $K_{p}$ index which is a three-hour average. Thus we have another reason to expect that the veracity of these two models is inferior to results from T96 and T01. By comparison, for all the substorms studied, the closest onset distance of the magnetic field line which threads the auroral onset position as computed with T87 was $5.3 R_{E}$, compared to $6.0 R_{E}$ for T89. The furthest onset distance was $16.0 R_{E}$ and $18.4 R_{E}$, respectively. The mean onset distances for all substorms were $7.3 R_{E}$ and $9.1 R_{E}$, respectively. The mean distances are consistent with results of Frank and Sigwarth (2000). The statistical results from T96 and T01 were quite different since some cases mapped far downtail because of 
Table 2. Model coefficients of the best fit between onset location and dipole tilt. The model was $X_{G S M}=A \theta+B$, where $\theta$ is the dipole tilt angle. The third column indicates the correlation coefficient for the best fit.

\begin{tabular}{cccc}
\hline & $\mathrm{A}$ & $\mathrm{B}$ & $\mathrm{r}$ \\
\hline $\mathrm{T} 87$ & -4.156 & -127.7 & 0.10 \\
T89 & -2.230 & -72.5 & 0.26 \\
T96 & -1.590 & -57.36 & 0.83 \\
T01 & -1.631 & -58.14 & 0.90 \\
\hline
\end{tabular}

very stretched magnetic field lines. This could be related to the field-aligned currents in these models, since these have been shown to significantly modify the tail geometry (Donovan, 1993). For all substorms, the minimum and maximum onset distances for T96 and T01, respectively, were $5.9 R_{E}$ and 5.5 $R_{E}$, and $65.8 R_{E}$ and $29.3 R_{E}$. The range of the results for T01 encompass previous observations (Nishida et al., 1996) that place the average neutral line near $30 R_{E}$, but are not consistent in the sense that the onset location from T01 is much closer to the earth with an average of $14.1 R_{E}$. They are therefore more consistent with other results that place the onset location near the ring current (Samson et al, 1992; Frank and Sigwarth, 2000); i.e. the results support the CD model, not the NENL model.

The results of this research provide a possible explanation for sometimes contentious discussions about the location of substorm onset which is indicated most clearly in its ionospheric footprint. Within the narrow range of dipole tilts examined (only $20 \%$ of parameter space was examined) we found that the downtail distance of the substorm onset was strongly dependent on the dipole tilt for T96 and T01. The more negative the dipole tilt the closer to the Earth the onset typically occurred. This result also has interesting implications regarding the cause of magnetospheric substorms. Substorms are known to occur during almost all levels of magnetospheric activity, especially during active times. The question of whether they are externally driven or primarily an internal magnetospheric instability is one that remains unresolved. It is clear that solar wind conditions influence substorms, for example, as is well-known and indicated again in this study, one can see that there is a higher probability for substorms during southward interplanetary magnetic field (Fig. 4), but this says nothing about the location of the onset. For the range considered our modeling indicates dipole tilt angle strongly influences the location of the substorm onset.

Our results can be summarized as follows:

1. There are onset dependencies on dipole tilt $/ \mathrm{P}_{d y n} / \mathrm{B}_{z}$ for T96 and T01; the trend with $\mathrm{P}_{d y n}$ and $\mathrm{B}_{z}$ is qualitative but the relationship is strong for tilt, with a large correlation coefficient. Less clear dependencies are observed for T89 (with $K_{p}$ ) and nothing can be said about dependencies for $\mathrm{T} 87$.

2. For T96 and T01 there is a strong linear dependence between tilt and downtail distance; as tilt becomes less negative onsets occur further downtail.

3. Substorm ignition occurs preferentially before midnight.

4. Substorms that are initiated before $30 \mathrm{~min}$ after midnight map to the dusk side of the magnetotail $(Y>0)$. This indicates some twisting or asymmetry of the magnetotail.

5. The model that provides the expected best estimate (T01) for onset location typically gives onsets on the duskside at an average downtail distance of $\mathrm{R}=14.1 R_{E}$.

6. Substorms can be initiated in the magnetotail from within the ring current region to approximately $30 R_{E}$.

It should be emphasized that our results should be interpreted with caution since all of the substorms considered here occurred during the winter months, and featured negative dipole tilts. As such, one should be cautious about extrapolating this trend. For example, as the dipole tilt approaches $0^{\circ}$ the onset location is close to $-60 R_{E}$, which is completely unrealistic. It is more likely that the true relationship is nonlinear and the results given here fit a only a small subsection of parameter space where a linear relationship holds. It is well known that there are seasonal effects related to space weather (Russell and McPherron, 1973) and we will need to perform similar analysis to examine whether the observed relations are the same for a larger range of dipole tilts that occur during other seasons when photometer data are more difficult to obtain. Second, the results are dependent on Tsyganenko models that are based on averages and are therefore inherently inaccurate, although this weakness is perhaps ameliorated by the statistical approach we have followed.

Acknowledgements. The CANOPUS array is funded by the Canadian Space Agency. This material is based on work supported by the National Science Foundation under Grants No. ATM-0449403 and DMS-0417690. SDG

Topical Editor T. Pulkkinen thanks M. Fillingim and J. Bortnik for their help in evaluating this paper.

\section{References}

Baker, K. B. and Wing, S.: A new magnetic coordinate system for conjugate studies at high latitudes, J. Geophys. Res., 94, 9139_ 9143, 1989.

Baker, D. N., Pulkkinen, T. I., Angelopoulos, V., Baumjohann, W., and McPherron, R. L.: The neutral line model of substorms: Past results and present view, J. Geophys. Res., 101, 12 975-13/,010, 1996. 
Baker, D. N. and Li, X.: Relativistic electron flux enhancements during strong geomagnetic activity, in: Disturbances in Geospace The Storm-Substorm Relationship, (edited by: Sharma, A. S., Kamide, Y. and Lakhina, G. S., AGU monograph, 217-230, 2003.

Baumjohann, W., Kokubun, S., Mukai, T., et al.: Substorm dipolarization and recovery, J. Geophys. Res., 104, 24 995-25000, 1995.

Birn, J. and Hesse, M.: Details of current disruption and diversion in simulations of magnetotail dynamics, J. Geophys. Res., 101, $15345-15358,1996$.

Blanchard, G. T., Lyons, L. R., and Samson, J. C.: Accuracy of using $6300 \AA$ auroral emission to identify the magnetic separatrix on the nightside of Earth, J. Geophys. Res., 102(A5), 9697-9704, doi:10.1029/96JA04000, 1997.

Cheng, C. Z. and Lui, A. T. Y.: Kinetic ballooning instability for substorm onset and current disruption observed by AMPTE/CCE, Geophys. Res. Lett., 25, 4091-4094, 1998.

Donovan, E. F. : Modeling the magnetic effects of field-aligned currents, J. Geophys. Res., 98, 13 529-13 543, 1993.

Dubyagin, S. V., Sergeev, V. A., Carlson, C. W., Marple, S. R., Pulkkinen, T. I., and Yahnin, A. G.: Evidence of near-Earth breakup location, Geophys. Res. Lett., 30, 1282, doi:10.1029/2002GL016569, 2003.

Erickson, G. M., Maynard, N. C., Burke, W. J., Wilson, G. R., and Heinemann, M. A.: Electromagnetics of substorm onsets in the near-geosynchronous plasma sheet, J. Geophys. Res., 105, 25 265-25 290, 2000.

Frank, L. A. and Sigwarth, J. B.: Findings concerning the positions of substorm onsets with auroral images from the Polar spacecraft, J. Geophys. Res., 105, 12 747-12 761, 2000.

Friedrich, E., Samson, J. C., Voronkov, I., Rostoker, G. et al.: Dynamics of the substorm expansive phase, J. Geophys. Res., 106, 13 145-13 163, 2001.

Jayachandran, P. T., MacDougall, J. W., St-Maurice, J.-P., Moorcroft, D. R., Newell, P. T., and Prikryl, P.:Coincidence of the ion precipitation boundary with the HF E region backscatter boundary in the dusk-midnight sector of the auroral oval, Geophys. Res. Lett., 29(8), 1256, doi:10.1029/2001GL014184, 2002.

Kan, J. R., Craven, J. D., and Akasofu,S.-I.: MHD simulations of substorm dynamics including an inner magnetotail, in: Proceedings of the 2nd International Conference on Substorms, edited by: Hesse, M., Birn, J., Baker, D. N., and Pulkkinen, T. I., University of Alaska press, Fairbanks, 237-243, 1994.

Kaufmann, R. L.: Substorm currents: growth phase and onset, J. Geophys. Res., 92, 7471-7486, 1987.

Kubyshkina, M. V., Sergeev, V. A., and Pulkkinen, T. I.: Hybrid Input Algorithm: An event-oriented magnetospheric model, J. Geophys. Res., 104(A11), 24977-24994, doi:10.1029/1999JA900222, 1999.

Liou, K., Meng, C.-I., Lui, A. T. Y., Newell, P. T., Brittnacher, M., Parks, G., Reeves, G. D., Anderson, R. R., and Yumoto, K.: On relative timing in substorm onset signatures, J. Geophys. Res., 104(A10), 22 807-22 818, 10.1029/1999JA900206, 1999.

Liou, K., Meng, C.-I., Newell, P. T., Takahashi, K., Ohtani, S.-I., Lui, A. T. Y., Brittnacher, M., and Parks, G.: Low-latitude Pi 2 pulsations as possible indicators of substorm onset: A survey using Polar ultraviolet imagery, J. Geophys. Res., 105, 24952505,2000
Liou, K., Meng, C.-I., Newell, P. T., Lui, A. T. Y., Reeves, G. D., and Belian, R. D.: Substorm injections with auroral expansions, J. Geophys. Res., 106, 5873-5882, 2001.

Lu, G., Tsyganenko, N. A., Lui, A. T. Y., Singer, H. J., Nagai, T., and Kokubun, S.: Modeling of time-evolving magnetic fields during substorms, J. Geophys. Res., 104(A6), 12 327-12338, 1999.

Lui, A. T. Y.: A synthesis of magnetospheric substorm models, J. Geophys. Res., 96, 1849-1856, 1991.

Lui, A. T. Y., Williams, D. J., McEntire, R. W., Ohtani, S., Zanetti, L. J., Bristow, W. A., Greenwald, R. A., Newell, P. T., Christon, S. P., Mukai, T., Tsuruda, K., Yamamoto, T., Kokubun, S., Matsumoto, H., Kojima, H., Murata, T., Fairfield, D. H., Lepping, R. P., Samson, J. C., Rostoker, G., Reeves, G. D., Rodger, A. L., and Singer, H. J.: Multipoint study of a substorm on February 9, 1995, J. Geophys. Res., 103(A8), 17333-17344, doi:10.1029/97JA02632, 1998.

Lyons, L. R., Zesta, E., Samson, J. C., and Reeves, G. D.: Auroral disturbances during the January 10, 1997 magnetic storm, Geophys. Res. Lett., 27(20), 3237-3240, doi:10.1029/1999GL000014, 2000.

Miyashita, Y., Machida, S., Nishida, A., Mukai, T., Saito, Y., and Kokubun, S.: GEOTAIL observations of total pressure and electric field variations in the near and mid-distant tail associated with substorm onsets, Geophys. Res. Lett., 26(6), 639-642, doi:10.1029/1999GL900031, 1999.

Nagai, T., Fujimoto, M., Saito, Y., Machida, S., Terasawa, T., Nakamura, R., Yamamoto, T., Mukai, T., Nishida, A., and Kokubun, S.: Structure and dynamics of magnetic reconnection for substorm onsets with Geotail observations, J. Geophys. Res., 103(A3), 4419-4440, doi:10.1029/97JA02190, 1998.

Nishida, A., Mukai, T., Yamamoto, T., Saito, Y., and Kokubun, S.: Magnetotail convection in geomagnetically active times, 1. Distance to the neutral lines, J. Geomag. Geoelectr., (48), 489-501, 1996.

Ohtani, S., Takahashi, K., Sanetti, L. J., McEntire, R. W., et al.: Initial signatures of magnetic field and energetic particle fluxes at tail reconfiguration: Explosive growth phase, J. Geophys. Res., 97, 19311-19324, 1992.

Ohtani, S., Creutzberg, F., Mukai, T., Singer, H., Lui, A. T. Y., Nakamura, M., Prikryl, P., Yumoto, K.,and Rostoker, G.: Substorm onset timing: The December 31, 1995, event, J. Geophys. Res., 104(A10), 22 713-22 728, doi:10.1029/1999JA900209, 1999.

Pulkkinen, T. I., Baker, D. N., Wiltberger, M., Goodrich, C., et al.: Pseudobreakup and substorm onset: Observations and MHD simulations compared, J. Geophys. Res., 103, 14 847-14 854, 1998.

Pulkkinen, T. I.: A study of magnetic field and current configurations in the magnetotail at the time of a substorm onset, Planet Space. Sci., 39, 833-845, 1991.

Pulkkinen, T. I.,. Baker, D. N, Pellinen, R. J., Murphree, J. S., and Frank, L. A.: Mapping of the auroral oval and individual arcs during substorms, J. Geophys. Res., 100, 21 987-21 994, 1995.

Pulkkinen, T. I., Baker, D. N., Cogger, L. L., Frank, L. A., Sigwarth, J. B., Kokubun, S., Mukai, T., Singer, H. J., Slavin,J. A., and Zelenyi, L.: Spatial extent and dynamics of a thin current sheet during the substorm growth phase on December 10, 1996, J. Geophys. Res., 104, 28 475-28 490, 1999. 
Reeves, G. D. and Henderson, M. G.: the storm-substorm relationship: ion injections in geosynchronous measurements and composite energetic neutral atom images, J. Geophys. Res., 106, 5833-5844, 2001.

Reeves, G., Henderson, M. G., Skoug, R. M., Thomsen, M. F., et al.: IMAGE, POLAR, and geosynchronous observations of substorm and ring current ion injection, in: Disturbances in Geospace The Storm-Substorm Relationship, edited by: Sharma, A. S., Kamide, Y., and Lakhina, G. S., AGU monograph, 91-102, 2003.

Rostoker, G., Samson, J. C., Creutzberg, F., Hughes, T. J., et al.: CANOPUS - A ground-based instrument array for remote sensing the high latitude ionosphere during the ISTP/GGS program, Space Sci. Rev., 71, 743-760, 1995.

Russell, C. T. and McPherron, R. L.: Semiannual variation of geomagnetic activity, J. Geophys. Res., 78, 92-108, 1973.

Samson, J. C., Lyrons, L. R., Newell, P. T., Creutzberg, F., et al.: Proton aurora and substorm intensifications, Geophys. Res. Lett., 19, 2167-2174, 1992.

Samson, J. C.: Mapping substorm intensifications from the ionosphere to the magnetosphere, in: Proceedings of the International Conference on Substorms 2, edited by: Kan, J. R., Craven, J. D., and Akasofu, S.-I., Univ. Alaska, 189, 1994.

Samson, J. C.: Nonlinear, hybrid, magnetohydrodynamic instabilities associated with substorm intensifications near the Earth, in: Substorms-4: International Conference on Substorms-4, Lake Hamana, Japan, March 9th-13, 1998, edited by: Kokubun, S. and Kamide, Y., Kluwer Academic, Norwell, Mass., 505-509, 1998.

Schödel, R., Nakamura, R., Baumjohann, W., Mukai, T., et al.: Rapid flux transport and plasma sheet reconfiguration, J. Geophys. Res., 106, 8381-8390, 2001.

Shiokawa, K., Baumjohann, W., Haerendel, G., et al.: Breaking of high-speed flows in the near-Earth tail, Geophys. Res. Lett., 24, 1179-1182, 1997.

Tsyganenko, N. A.: Global Quantitative Models of the Geomagnetic Field in a Cislunar Magnetosphere for Different Disturbance Levels, Planet. Space. Sci., 35, 1347-1358, 1987.
Tsyganenko, N. A.: A magnetospheric magnetic field model with a warped tail current sheet, Planet. Space. Sci., 37, 5-20, 1989.

Tsyganenko, N. A.: Modelling the Earth's magnetospheric magnetic field confined within a realistic magnetopause, J. G. R., 100, 5599-5612, 1995.

Tsyganenko, N. A.: Effects of the solar wind conditions on the global magnetospheric configuration as deduced from data-based models, in: Proceedings: Third International Conference on Substorms (ICS-3), edited by: Rolfe, E. J. and Kaldeich, B., European Space Agency Spec. Publ., ESA SP-399, 181-185, 1996.

Tsyganenko, N. A.: A model of the near magnetosphere with a dawn-dusk asymmetry, 1. Mathematical structure, J. Geophys. Res., 107, doi:10.1029/2001JA000219, 2002a.

Tsyganenko, N. A.: A model of the near magnetosphere with a dawn-dusk asymmetry, 2. Parameterization and fitting to observations, J. Geophys. Res., 107, doi:10.1029/2001JA000220, 2002b.

Voronkov, I., Friedrich, E., and Samson, J. C.: Dynamics of the Substorm Growth Phase as Observed using CANOPUS and SuperDARN Instruments, J. Geophys. Res., 104, 28 491-28 505, 1999.

Wanliss, J. A., Samson, J. C., and Friedrich, E.: On the use of photometer data to map dynamics of the magnetotail current sheet during substorm growth phase, J. Geophys. Res., 105, $27673-$ 27684.2000.

Wanliss, J. A., Rankin, R., and Samson, J. C.: Field line resonances in a stretched magnetotail: CANOPUS optical and magnetometer observations, J. Geophys. Res., 107(0), doi:10.1029/2001JA000257, 2002.

Yoon, P. H., Dreake, J. F., Lui, A. T. Y., et al.: Theory and simulation of Kelvin-Helmholtz instability in the geomagnetic tail, J. Geophys. Res., 101, 27 327-27 340, 1996.

Zhou, X.-W., Russell, C. T., Le, G., Fuselier, S. A., and Scudder, J. D.: The polar cusp location and its dependence on dipole tilt, Geophys. Res. Lett, 26, 3, 429-432, 1999. 